\title{
Article
}

\section{"We've Always Been Engineers:" Indigenous Student Voices on Engineering and Leadership Identities}

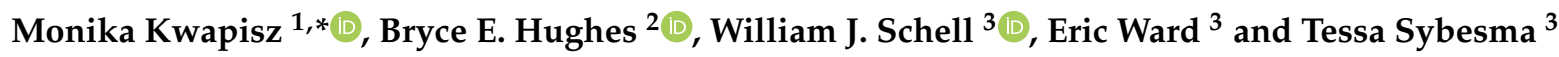 \\ 1 Department of Industrial and Systems Engineering, University of Washington, Seattle, WA 98101, USA \\ 2 Department of Education, Montana State University, Bozeman, MT 59717, USA; bryce.hughes@montana.edu \\ 3 Department of Mechanical and Industrial Engineering, Montana State University, Bozeman, MT 59717, USA; \\ wschell@montana.edu (W.J.S.); ward.eric24@gmail.com (E.W.); tesssyb@gmail.com (T.S.) \\ * Correspondence: mkblue@uw.edu
}

check for

updates

Citation: Kwapisz, M.; Hughes, B.E.; Schell, W.J.; Ward, E.; Sybesma, T.

"We've Always Been Engineers:"

Indigenous Student Voices on

Engineering and Leadership

Identities. Educ. Sci. 2021, 11, 675.

https://doi.org/10.3390/

educsci11110675

Academic Editors: Sylvia Hurtado and Krystle Palma Cobian

Received: 1 September 2021

Accepted: 19 October 2021

Published: 22 October 2021

Publisher's Note: MDPI stays neutral with regard to jurisdictional claims in published maps and institutional affiliations.

Copyright: (c) 2021 by the authors. Licensee MDPI, Basel, Switzerland. This article is an open access article distributed under the terms and conditions of the Creative Commons Attribution (CC BY) license (https:/ / creativecommons.org/licenses/by/ $4.0 /)$.

\begin{abstract}
Background: How do Indigenous engineering students describe their engineering leadership development? The field of engineering has made only slow and modest progress at increasing the participation of Indigenous people; an identity-conscious focus on leadership in engineering may help connect the practice of engineering with Indigenous students' motivations and values. Methods: This study utilized a grounded theory qualitative approach to understand how Indigenous engineering students at a U.S.-based university experience engineering leadership. We explored the experiences of four Indigenous engineering students through one interview and one focus group. Results: Students pointed out how Indigenous peoples had long engaged in engineering work before contact with European settlers, and they saw an opportunity for leadership in applying their engineering knowledge in ways that uplifted their home communities. Conclusion: In addition to ways that engineering programs can better support Indigenous students who aspire to become practicing engineers, our study pointed to new directions engineering programs could take to frame engineering work as providing a toolkit to improve one's community to leverage a wider set of motivations for entering engineering among many different communities underrepresented in engineering, including Indigenous students.
\end{abstract}

Keywords: engineering; engineering identity; Indigenous STEM; Indigenous students; leadership identity; Native American students; STEM; STEM inclusion

\section{Introduction}

The engineering profession in the USA continues to struggle with the seemingly intractable problem of improving representation in the profession, e.g., [1,2]. During recent years, engineering education researchers focused on student retention have seen promising results through the application of identity-based approaches, e.g., [3,4]. However, much of the identity-based research in engineering utilizes those groups most represented in the field [5]. This work seeks to broaden that perspective with a specific focus on the experiences and perspectives of Indigenous students enrolled in engineering programs. Specifically, we employ qualitative methods to explore the perspectives of Indigenous engineering students on the relationship between three aspects of identity: Indigenous identity, engineering identity, and leadership identity.

Furthermore, examining the role of the engineering profession throughout US history, the engineering profession has largely served the nation's colonial goals around expanding resource extraction and exploitation. How well does the engineering profession serve the needs of Indigenous communities in the USA? Many engineering academic programs trace their history to the Morrill Act of 1862, which promoted the "mechanical arts" (now known as engineering) as an important field of study to be taught in the land-grant colleges the act established in each state. These new states, and the lands within them that were sold to raise money for these land-grant colleges, were only "available" to the US government through 
the forced removal of the First Nations that called these places home [6]. As the engineering profession reckons with this historical legacy and struggles with the seemingly intractable problem of improving representation in the profession, we propose that centering the voices of Indigenous engineering students, against the backdrop of First Nations' continued work to reassert sovereignty and self-determination, can help decolonize engineering training and practice in ways that offer liberatory possibilities for the purposes engineering could serve to improve society.

\section{Positionality}

This study was conducted at a university in the USA, which situates our exploration into Indigeneity within that sociohistorical context. Our participants are from communities affected primarily by settler colonial actions taken by the US government, which may reflect those of other Indigenous peoples in other parts of the world but will also uniquely reflect this setting. Furthermore, although the research was conducted at a university in the USA recognized for its commitment to Indigenous students, the university is a predominantly white institution (PWI), and the main authors of this study are non-Indigenous and white. We are not directly affected by the systemic abuses on Indigenous communities and individuals. The cultural genocide Native Americans experienced in the residential school system sought to eliminate Indigenous knowledge and promote colonizer epistemology [7] The authors acknowledge that they, as white academics, are part of settler colonialization on the ancestral lands taken to establish the land-grant university system [6].

The primary three authors are a non-binary student researcher and two professors who are men. The additional student co-authors who assisted with data collection and early drafts of the work are a white woman and a Native Hawaiian man. As a predominately white research team, we hope to highlight the words of the Indigenous participants in our study (as will be discussed in the Trustworthiness section) and hope that Indigenous researchers will continue research into the field of engineering leadership identity development.

\section{Literature Review}

This work seeks to bring together several somewhat disparate sub-fields of study within engineering education. Since the primary focus of this study is an exploration of the ways in which an Indigenous identity is related to engineering and leadership identities, we must ground the study in the literature of indigenous identity, engineering identity, leadership identity, and the nascent literature in engineering leadership identity. To do this, we start with brief overviews of the most common areas of the literature, engineering and leadership identity, before diving into the areas most related to this work, engineering leadership and Indigenous identities.

This study builds on the authors' previous work in the field of engineering leadership identity $[8,9]$. That work utilized qualitative methods drawing from a varied sample of engineering undergraduates, to explore the intersection of engineering identity development and leadership identity development. Little work exploring these the same subjects exists specifically for Indigenous students, an oversight likely due to the frequent subsumption of Indigenous students into research on racial/ethnic minoritized students [10]. Therefore, we must contextualize this work within the field of Indigenous education and Indigenous Identity.

\subsection{Engineering and Leadership Identities in Engineering Education}

Identity is a concept that reflects how an individual is positioned relative to broader society. Situated learning theory suggests that identity is central to human development as learning of all types is constructed within and defined by context [11]. Numerous aspects of identity continue to gather interest by engineering educators and researchers. This interest is driven by the positive effects that development of an engineering identity appears to generate, including improvements in motivation, self-efficacy, and persistence in the field $[4,5,12-14]$. For this work, we consider engineering identity to be a form of 
professional identity [5] that is largely authored by students through their experiences in engineering education during college [15].

Similar to engineering identity, leadership identity can be defined in a number of ways, depending on the lens (e.g., developmental psychology, sociocultural, etc.) utilized to develop the definition. When considering leadership identity in college students, we utilize a commonly accepted approach from Komives et al.'s [16] Leadership Identity Development (LID) model. Grounded in developmental psychology, the LID presents a staged development model based on the core finding that students' leadership identity develops when they deepen their understanding of what constitutes leadership. A key aspect of this growth is when students move from a positional to a relational definition of leadership [16].

\subsection{Indigenous and Engineering Leadership Identities}

An important and burgeoning body of research has demonstrated the ways that traditional Indigenous knowledges, particularly those of Native American communities, have been excluded from engineering and other STEM degree programs. This literature demonstrates the resulting dissonance Indigenous students experience when encountering the dominant epistemology and culture when studying these fields.

Tension between the learning frameworks of Indigenous communities and mainstream academia was recognized by participants in a study of the experiences of Native American students in science, engineering, and health fields. These students also expressed the dominant epistemology in these fields did not value and respect their knowledge and values. For example, a student felt deep discomfort when using human bones from cadavers in their classes due to cultural beliefs about handling the dead. Other students in this study recognized their Indigenous ancestors as mathematicians and engineers in ways not recognized by mainstream STEM fields. As such, these traditions and ways of knowing are not acknowledged in the classroom [17].

Foster and Jordan [18] determined that Indigenous ways of knowing STEM concepts should easily integrate with mainstream engineering knowledge to make engineering more accessible for Indigenous students. In comparing Diné and engineering philosophies of learning, they explained that one Navajo method of internalizing knowledge entails thinking, planning, living or implementing, and reflecting and assuring. Similarly, one version of the engineering design method instructs the engineer to ask, imagine, plan, create, and improve. The two are not entirely dissimilar frameworks. Foster and Jordan's [18] work not only aligned with Cech et al.'s [17] point regarding STEM concepts as always having been traditional Indigenous knowledges but see this alignment as an opportunity to broaden the participation of Indigenous students in engineering.

In addition to reclaiming traditional knowledges in engineering, Indigenous students often view studying engineering and other STEM fields as contributing to their Nations ${ }^{\prime}$ perseverance. A study of three Navajo, Tohono O'odham participants on their cultural connections to engineering asked participants for their perceptions of engineering and encouraged the participants to connect that definition to their culture. The emergent themes show that these Indigenous engineers see engineering as "a cultural strategy to survive" and "a process for community development." Whether it be due to the perceived social mobility that an engineering career may offer or a deeper understanding of the issues facing First Nations in the USA, Indigenous students may be motivated to study engineering for different reasons than their peers, reasons essential to their persistence in engineering programs. Taken together, though the published literature on Indigenous engineering identity is still developing and recognizing that much of the knowledge on Indigenous engineering is present in forms other than the written word, these studies represent many key findings regarding Indigenous engineering identity, leading the way for much future work in this area. 


\subsection{Indigenous Student Leadership}

The studies found in the literature on Indigenous student leadership primarily focus on student organizations and are not specific to STEM students or the process of leadership development. Rather, these findings are relevant to our study in that they reveal the ways leadership is conceptualized differently through Indigenous epistemologies. Minthorn [19] conducted focus groups with Indigenous student leaders yielding three overarching words students used to describe Indigenous leadership: commitment, community, and collaboration. The Indigenous student leaders interviewed in that work showed an expansive definition of leadership. They saw their leadership as a way of representing their nations and keeping their cultures alive, being a role model, and a handful of other factors that may not present themselves in a more individualistic view of leadership. The students also described the motivation and dedication it takes to be an Indigenous student leader, especially at a PWI [19].

Regarding our context in the USA, education and leadership in relation to Indigenous people are more well studied subjects but sparse when it comes to STEM subjects. Education and other fields need more Indigenous leaders "who are knowledgeable about their culture and secure in their identity" [20]. Leaders should be secure in their identity because, according to Comanche author John Tippeconnic, the same qualities that make him a good Comanche are the qualities that make a good leader. One's values reflect in their leadership as a display of one's identity: "Comanche values promote leadership that is cultural, ethical, inclusive, collaborative, shared or team based, diverse, and accepts and promotes the broader worldview of education" [21].

One narrative essay stands out as most relevant in the academic discourse on Indigenous engineering leadership identity development. In her essay "Walking in Beauty on an Ever-Changing Path: A Leadership Perspective from a Native American Woman Engineer" Sandra Begay-Campbell [22], "a member of the Zuni clan (Náneesht'ézhí Táchii'nii) of the Navajo Nation born as a gift to [her] father's clan, the Bitterwater Clan (Tó dích'íinii)," describes engineering leadership that is informed by her identity (p. 150). Begay-Campbell documents her development as an engineer and a leader through the Beauty Way Chant, a Navajo holistic teaching, leading her back to a path of self-defined success despite hardship. Other points along Begay-Campbell's identity development path include growing up in a matrilineal society, her connection to fellow underrepresented minority STEM students, and understanding the changing seasons in her career. Although not an undergraduate student perspective, Begay-Campbell's documentation of her journey through engineering and leadership helps uncover ways Indigenous students' understandings of leadership may differ from mainstream (white) perspectives.

\section{Theoretical Framework}

The theoretical framework informing this study is founded in the perspectives that shaped the overall engineering leadership project. This is expanded with essential understandings about Native Americans pertinent to understanding the unique context of Indigenous students in the USA developing engineering leadership identity. We will first briefly summarize the community of practice and leadership identity development models that shaped the overall research project, and then we will articulate our essential understandings about Indigeneity that guided this analysis. Finally, we will reveal how the two connect to help us articulate what we learned from our participants in this phase of the project.

Our understanding of engineering leadership identity integrates Lave and Wenger's [23] communities of practice (COP) model with Komives et al.'s [16] leadership identity development model (LID). The COP model is used to highlight the situatedness of engineering education and its interest in professional identity formation while the core contribution from LID is acknowledgement that college students develop a sense of leadership identity as they come to internalize an understanding of leadership as a process. Lave and Wenger [23] described the process of learning a specific practice, such as the profession 
of engineering, as situated learning, or learning that results from direct engagement in a shared practice. Novice learners engage with a given practice through legitimate peripheral participation in a community of shared practice. Over time, they become more central participants as they master the practice and become full members of the community. It is at this point where they have developed competence within the shared practice, have mastered performance of that practice, and have earned recognition from others in the practice - as well as themselves - as members of that community that they identify with that practice [24,25]. In engineering, this stage is referred to as engineering identity.

As novices become more central practitioners within a community of practice, we also posit that they might start to be recognized as leaders within their communities of practice. However, simply viewing one as a leader due to being a central participant in a community of practice limits the definition of leadership. Instead, we use the LID model to view the exercise of leadership as a process that can be shared by anyone in a community opens the potential of all members to contribute to the goals and interests of the community. A central argument of Komives et al.'s [16] LID model is that this transition-moving from seeing leadership as a behavior exercised by a person holding a specific position of authority to seeing leadership as a process shared within a community or organization-is the point where college students start to see themselves as leaders. The LID model shows college students progressing through six stages on their way to developing a solid sense of leadership identity, and the transition point between the third and fourth stages is where they make this shift in their thinking about leadership. We have hypothesized in earlier work that bringing legitimate peripheral participants who understand leadership as a process into a community of practice could blend their sense of leadership identity with their burgeoning professional identities in generative ways for the communities in which they practice $[4,8,9]$.

The concepts of community of practice and leadership as process complement essential understandings about Indigenous leadership from the literature on Native American perspectives on leadership. For example, Minthorn [19] acknowledges community engagement and social responsibility as integral aspects to Native American leadership. Furthermore, team-based leadership in particular complements how leadership is exercised within Native American communities [26], and Native college students experience these values through an emphasis on leadership that serves their home communities [20]. Some of these values were developed through the histories and traditions of the myriad of nations collectively referred to as Native Americans; some of these values were developed as a necessity to maintain resilience through the historical trauma from contact between European settlers and the Indigenous nations of North America.

That said, Indigenous people are not a monolith. Although many of these shared qualities can be observed among the various Indigenous nations in the USA, each First Nation has a distinct history, culture, traditions, and knowledges that distinguish its identity among other nations [27]. No single person speaks on behalf of all Indigenous people, or even the entire nation in which they may be enrolled. Furthermore, the relationship between the US government and each individual nation can complicate the experience of Indigenous identity for any person whose ancestors are indigenous to North America $[28,29]$. While many nations are federally recognized, some might be recognized by state governments but not the federal government, and other nations are still seeking recognition to gain access to resources [30]. Nations have also been coerced into establishing standards for people to claim enrollment as a member, practices that may allow some descendants of Indigenous people to continue to claim enrollment in a nation and bar others from such claims. We allowed prospective participants to decide for themselves if they identified as Native American or Indigenous in some way as they were deciding to participate in this study. 


\section{Methods}

In order to understand how Indigenous students describe their engineering leadership identity development in their own words, we conducted a qualitative study to explore their experiences, using an approach similar to that of Minthorn [19]. This study is a piece of a larger grounded theory study seeking to explain how undergraduate engineering majors develop engineering leadership identity and built off the methods of that study. We conducted specific outreach to Native American students at one of our three study sites. This site is a university known for graduating Native American students in STEM.

We conducted one focus group and one interview with Indigenous students focused on their experiences of engineering identity, leadership identity, and engineering leadership identity. We first conducted the interview with an Indigenous student who then helped us organize and facilitate the focus group for this study. Data were collected in spring 2020, just as the COVID-19 pandemic was emerging in the USA.

Overall, four Indigenous engineering undergraduates participated in this study. To protect their confidentiality, they chose pseudonyms to represent them in the findings: Ashley, Ethan, Victor, and J-man. Participants included members of the Crow and Blackfeet nations, a student with Aztec ancestry, and a Native Hawaiian. Three participants were men and one a woman. Furthermore, three of the four participants were non-traditional students. They had started or completed other degrees before enrolling in their current engineering programs. For example, one student had started in mechanical engineering 10 years previously but described that time as being in "party mode." He chose to come back to school after working in the food service industry. Another student was enrolled in a tribal college before transferring to the four-year institution.

The interview protocol used in previous focus groups, which included a variety of students, were modified slightly for the Indigenous focused part of the project. Students were asked to share their Indigenous nation and cultural backgrounds at the beginning of the session. Follow-up questions prompted participants to contextualize their experiences in their Native culture and upbringing. The protocol then covered areas such as engineering identity, leadership identity, and engineering leadership, with questions that overlapped with those of Anderson and Jordan [31]. Interviews were professionally transcribed and imported into NVivo qualitative analysis software for analysis.

\section{Analysis}

Analysis began by coding the transcripts in an emergent manner to center the words of the participants in the analysis. Two authors (first and second author) of this work read both transcripts several times to familiarize themselves with the data and then wrote memos and margin notes based on the potential codes that were emerging. These two authors came to consensus around a set of five broad codes to apply to both transcripts.

Next, the third author coded the two transcripts deductively using the codebook developed from the larger grounded theory project. This second phase was to inform the analysis as to places where the two codebooks - the new one created from the Indigenous student responses and the existing codebook from the overall grounded theory projectconverged. This phase of coding is best described as structural coding as it primarily followed the interview protocol.

Following these two coding phases, we examined points of convergence and divergence between the two sets of codes. Points of convergence, where coding overlapped to a great extent, helped us identity themes regarding how these four students experience their identities relative to engineering and leadership. Points of divergence offered important context for the themes, particularly around students' backgrounds and motivations for entering engineering. Excerpts from the transcripts were organized into four major themes, and significant statements within these excerpts were identified and woven together to develop each theme. 


\section{Trustworthiness}

We engaged several strategies to ensure the trustworthiness of the findings presented here. To ensure credibility, we focused explicitly on what participants said and not our understandings of the topic, using quotes to develop a rich, thick description of themes. One benefit of a small sample size was that we were able to engage more closely with the participants in the research process. We engaged in reflexivity to reveal our position as researchers in the research process, part of which can be found in the Positionality section of this paper. To ensure consistency, we worked as researchers to reach consensus on coding as well as thoroughly documenting the analysis process. For transferability, our use of thick description and other contextual information helps situate the findings relative to how they may transfer to other settings.

Finally, for relational accountability, we acknowledge that a unique attention to research ethics is not only warranted but essential to ensure our research process did not reproduce the exploitation common to research on Indigenous communities throughout USA history. First, our study was reviewed by the university Institutional Review Board and approved as exempt from review. Furthermore, we acknowledge our ethical obligation to ensure these findings are as beneficial to the communities this research represents, as we expect the findings to be in advancing scholarship on engineering leadership. As is common in Indigenous research methodologies, we will share these findings with offices at our study site that support Indigenous students in STEM, and we provided these findings to our participants to review. We will share these findings with offices at our study site that support Indigenous students in STEM, and we provided these findings to our participants to review. These relationships have the potential to then shape this work further, beyond what can be captured as a snapshot in one journal article.

\section{Results}

\subsection{What It Takes to Become an Engineer}

Participants nearly unanimously identified perseverance as an important aspect of becoming an engineer. Ashley stated, "It's applying yourself to a lot of very uncomfortable situations and forcing yourself to just stick it through because that's literally what I've been doing this entire college career." Students tackled problems through an iterative, trial-anderror process where discipline and grit helped them through. Self-doubt was one challenge they faced. In Ethan's words, "I mean there is a lot of things that do that but definitely using your brain more than what you thought you were possible to. Just that doubt that you have in yourself. I feel like inner doubt is the biggest demon in this program." Perseverance consisted of mustering the psychological resources to push through doubt and develop confidence in one's engineering abilities, as Victor stated: "No matter how many times you get knocked on your fucking ass, you still believe 'I can do this.'" J-man provided an example of his coping strategy for persevering through a difficult task:

There's times where you hit a wall and there's impossibility right in front of you. I don't know if this is possible to solve this... You get to where you're low on your own self. Then you remember it's not that bad. It's just something I have to go through....

The problem with experiencing doubt was it led students to question their place in engineering. Ethan summarized, "There's definitely a lot of situations you get put in where you're like, 'Am I really cut out for this?' It really tests who you are." At the same time, participants recognized that engineering education is also intentionally set up to mirror what engineering practice is like, including placing students in situations where they are not fully equipped with all the requisite knowledge needed for a successful outcome. As a result, Victor indicated that embracing a sense of vulnerability or humility was important:

And it's like in the sense that the vulnerability to be able to say, 'I don't know all the answers, I don't know right now. I don't know, but I am an engineer and I know how to fucking figure it out.' 
Ashley provided a specific example of lab work where she found she needed to develop self-directed learning skills to complete a project:

I work in a lab upstairs, and today I was given the job of creating a printed circuit board for our computer system. And [the professor] just kind of mentions the last grad student that worked on this it took them a year, and I was like, 'What? You want me to figure this out?' I don't even know how to make a printed circuit board, but I'm just forcing myself to learn.

At the end of the day, students pointed to the meaning behind the successes achieved from persevering through these seemingly intractable problems as contributing to their own sense of becoming engineers. Ethan described this process as "trusting yourself," and Victor noted that this process has helped him come to enjoy engineering. He said, "As you get better, you start to love it, but it really identifies the holes in my logical process where I'm failing and where I haven't been recognized and I need to work." He felt as though he were growing personally in addition to becoming a practicing engineer. Another participant pointed out that this desire to learn and grow as an individual is inherently an essential aspect of becoming an engineer. As Ethan put it:

"For me it's just not being scared of reaching the point you want because I feel like in this industry there's no stopping point because everything is changing, everything is moving. And so it allows you to grow within the industry. For me there's no end point, just more knowledge and I like that."

While previous life experience enriched the students' engineering development, the students regularly discussed difficulties once in engineering school. One of these difficulties was conflicts with peers in their home communities. J-man described responding to this conflict with a peer with love and empowerment, saying, "I don't think I'm better than you. But I think you could be better than you." The students' unique paths to engineering school were sometimes difficult, so they wanted others to persevere as they did to obtain an education.

\section{2. "I Get to Do That"}

In addition to recognizing the need to persevere through challenging or ambiguous engineering problems, students also felt it was fun to do engineering work. Much of what made it fun was the role of imagination in tackling their academic work. As Ethan put it, "You still get to be a kid because your imagination is what drives you to build what you want to do." Two students found the process of seeing what they imagined come to fruition as fun within itself, making the difficult work of persevering even more worth it. Ethan described, "Even though there are times that it is stressful, but you get to see something come to life that you just thought in your brain, and that's what I think is really cool." Seeing one project come to life opened J-man's eyes to the endless possibilities of engineering work: "One of the labs specifically was-we literally just put sodium hydroxide with oil and we made soap and there was a layer of biodiesel and I was like, 'Holy shit we can just make this here? We can just make anything here?"' What makes engineering fun is not just making imagined projects come to life but also being able to imagine new possibilities into the future.

Imagination and fun in engineering work make the possibility of a future career in engineering, and even engineering academic work, more enjoyable prospects. As Ethan put it, "I've got to make a living out of this, I've got to support people, but at the end of the day you get to kind of have fun with what you're doing." It is hard to deny that the prospect of an enjoyable career would not keep these students motivated to follow through with their goals. J-man described being entertained by his schoolwork: "And then I'll bust out my problems, my homework and it's fun. I don't know if it's fun, I don't know if it's fun to just me." Not all students would agree with this sentiment, but finding enjoyment in one's academic work would also be expected to help students persevere. 


\section{3. "Yo, I Did That"}

Not only does enjoyment of engineering work contribute to the process of becoming an engineer but so does the sense of accomplishment that comes with reaching a goal and how that accomplishment means one is developing confidence and competence in engineering. As Ethan put it, "I had an opportunity just to mess around with the robotics, and we wrote a code to make the arm move and pick up something, and I'm like, 'Yo, I did that."' What may have seemed to be an impossible or opaque task before learning the material and trying to write the code became a possible task after seeing a successful outcome from Ethan's effort. He went on to say, "Honestly it was when I wrote my first program.... Just seeing the code writing, and you're like, ah, it's just a bunch of math and numbers. And then you run it and then you see this thing walking across this screen and you're like, yeah." Students felt as though they knew what they were doing as a result of a successful outcome from their hard work.

The confidence and self-efficacy gained after successfully achieving an engineering outcome, coupled with the increased trust in one's own abilities to do new engineering projects, allowed participants to seek out the next challenge or opportunity afforded to them. J-man stated:

You just got to find something you're really interested in and just jump into it. Relish in the unknown. That's how I feel. That's one thing I'm really getting addicted to. I don't know what the hell this is and then you start learning stuff. I'll just work on it little by little and there's a point where things just start fitting. And it's like, 'Holy cow I think I know what to do now.'

Knowing what to do in engineering contributes greatly to one's sense of engineering identity.

\subsection{Engineering Identity}

In discussing their sense of engineering identity, participants generally adopted a stance of being on a trajectory toward becoming an engineer but not feeling like an engineer just yet. According to Ashley, "I'd just like to say I am an engineer in training. I mean I obviously don't know what I'm doing half the time." J-man described how a lack of clarity in his vision of his future engineering career was one factor inhibiting calling himself an engineer. He said, "My ultimate goal is I want to start my own company and I'm still working out an idea. I have too many ideas and that's the problem." For the most part, the students all viewed themselves as on a path toward becoming an engineer, but for various reasons, they still did not fully recognize themselves as engineers.

Victor was quite introspective when asked about engineering identity. He said, "Becoming that in here [points to chest] and believing that in here [points to chest] is totally different," acknowledging a difference between navigating the steps toward being able to work as an engineer and recognizing oneself as having become an engineer. He elaborated:

If you don't understand how the general relationships and your place in the physical world exists, and the limitations of what you can do and create within the physical world, then you can make some cool stuff, look-wise on paper, but it's never going to come to fruition.

In other words, becoming an engineer is more than mastering the knowledge and tools that engineers use in their work. Becoming an engineer also involves attention to the impact of engineering work on the social and natural world.

\subsection{Recognition as an Engineer}

Though they may not have immediately recognized themselves as engineers now, students saw themselves as people working to become engineers. Victor explained:

When you consider yourself an engineer, that means that you consider you've developed the capacity to be able to take whatever problem and break it down into its parts enough to put it into a way that you can understand it. 
The participants provided examples where it appeared they may be closer to being engineers than they recognized. Ethan described:

I looked at the code for an hour just trying to see... it just looks like a bunch of number and letters. And last night I was sleeping, and I woke up at three in the morning I was like, 'Oh shit.' And so I decided to work on it because in my head I was already thinking about it. It's just that nonconscious thinking, and so that's what's cool because before I never thought that I could just look at numbers and letters and pull a Rain Man and just... And then I looked at the code and did the assignment and that was cool. Then I told my roommates about it and they're like, 'You're weird.'

The movie Rain Man portrays a talented autistic savant, which is a harmful stereotype to the autistic community; for many people, this exceedingly gifted individual is the top-ofmind view of autism, a condition that encompasses people of various levels of care needs and mathematic talent [32]. Ethan saw himself in this stereotype because of his coding skill, which happened to be accompanied by a level of social rejection. He demonstrated the capacity to think like an engineer even though, at the time, he may not have recognized he could already do so.

Although participants may not have recognized themselves as engineers at the time of the interview, they acknowledged the role of being recognized by authorities in the field as contributing to a sense of engineering identity. As Victor put it:

"Being exposed that teachers say it's okay that you see yourself as an engineer, because until you... You may not feel it personally, but the sooner that you share that you do start to believe that, the sooner that you actually start to see exponential growth within your engineering endeavors."

In this case, he pointed out how engineering faculty hold a degree of authority in conferring legitimacy on students' claims to being engineers themselves.

Recognition from their peers as having developed engineering competence also validated their engineering identities, such as Victor saying, "Because I think when you do develop it, it's almost the sense of people come and ask you for help with a problem, or something like that." He added that someone can be recognized as an engineer in spite of following a nontraditional path into the field: "There's plenty of dudes that I've met that are geniuses and are brilliant engineers, and they've never gone to a traditional engineering school.... And they're doing stuff that a PhD should be doing, or whatever." In the end, though, what mattered was that these people were recognized by people in engineering as engineers.

Recognition from others was also observed when discussing the process of seeking out professional opportunities and asking for help. Ethan noted that engineers in industry were more willing to help engineering students:

A lot of people in the industry are there to help you because they've been that same person.

And so getting a job, whether it's you wanting to go back to get a masters or whatever it is, they'll help you in that career you decide to take.

He went on to describe how challenging himself to seek out opportunities was more productive than he expected it to be: "It's helped me personality-wise not to be scared to [introduce myself to people and] talk because when we had the career fair, I just wanted the experience, but I just ended up possibly scoring an internship out of it." Overall, though, it was important to participants to note that one does not have to rely on oneself alone to make it in engineering; relying on the community of practicing engineers is essential to succeed professionally as well. Being able to receive help from this community then adds that recognition as an engineer that is essential to developing an engineering identity.

\section{6. "We've Always Been Engineers"}

When asked about their perceptions of the field of engineering, and their own engineering identities, students raised two points about their experiences as Indigenous people 
that significantly connected their ethnic identities to their engineering identities. First, students recognized that Native people, particularly members of their specific communities or nations, are underrepresented in engineering. However, they reconstructed this underrepresentation as a source of aspiration to enter the field of engineering.

The underrepresentation of Indigenous people and their own nations specifically in professional settings was both discouraging and motivating for the students. They described the difficulty of not seeing people like them in higher-up positions. They were also motivated to become accomplished as Indigenous people in a predominantly white field. The students noted that many of their predominantly white peers had family members in engineering who encouraged them to be engineers, which was not typical of their experiences.

Not knowing many people who worked as engineers, or seeing many Indigenous engineers, meant they were less familiar with the field of engineering before college than they recognized many of their (white) peers were. Ethan, whose parents immigrated to the USA, said:

I feel like because you guys grew up in more of the States' culture you understood engineering. Where I, like my parents coming here, we don't learn these things off the bat like everyone else.

Ethan's understanding of what an engineer did was based on his observations working at a construction site. His perception from a young age was the engineer "sat in an office and did nothing" because of the closed trailers engineers often work in at construction sites. He saw his views switch from thinking the engineer was just a boss to an engineer being active in the design process.

In contrast, Victor described how having a white adoptive father who worked as an engineer influenced his decision to enter engineering:

I really, truly think that, I've thought about it more and more, I'm very fortunate, since I do know both of my family, I get to see them and just be like, 'Okay, well what would life have been like if I had been raised in that household versus this household?' And I don't think I would be an engineer if that were the case, to be honest.

This speculation reflected how different the decision to enter engineering might be for a person who has less familiarity with what the profession entailed.

Participants spoke about ways that they were able to become more familiar with the field of engineering as they started to make decisions about careers and majors to pursue and enter a four-year engineering program. J-man went on a high school job shadow at a mining company where he asked whether anyone in the company shared his tribal affiliation. It turned out that there was one engineering manager who did, and he described the impact of job shadowing this role model: "But he was the first [Crow engineer] I've ever seen that was just like me and for me that was, in retrospect, that's where I feel like I'm at. I'm the engineer now." The impression this role model had on J-man inspired him to want to pursue engineering and become a role model for other Indigenous youth.

A second path to becoming more familiar with the field of engineering was a summer bridge program facilitated by the university for tribal and community college students to transition into a four-year engineering major. Ashley pointed to this program as an essential resource to help her transition from the tribal college where she earned her associate's degree into her current engineering major:

... it was a transition summer program to get me from... my tribal college or community college and get into a four year. So, it was really good, and I had a good time and got ready and I felt super ready for school.

Programs such as these can help students build the assets that help them navigate and succeed in predominantly white engineering programs.

The irony, though, regarding students' stated lack of familiarity with engineering as a field became evident in a powerful exchange during the focus group setting. In J-man's words: 
... honestly, man, we've always been engineers. Native people. Look at all the problems we had back in the day. They weren't our problems. You know what I mean? We had fixes for everything. We had medicines, technology, most powerful weapons at the time.

Otherwise put, the engineering they were learning in their four-year engineering programs is based in knowledge circumscribed to reinforce and uphold settler colonialism, a system of engineering practice bounded to exclude other forms of engineering knowledge developed within other traditions. In this case, the recognition that engineering practice in the USA has developed in a manner that deliberately overlooks the potential contributions of Indigenous ways of knowing and traditional knowledges because of the displacement and subjugation of Indigenous peoples. J-man continued:

And after this we don't have to know everything. But we have the ability and the capacity to learn everything we need to understand something and do something about it. That's how I feel about it.

Although engineering as a field has embraced lifelong learning as a professional value over the past several decades, J-man's statement captures his point that engineering knowledge as currently construed is both incomplete and limited in its delegitimating of other forms of knowledge. To him the field of engineering could advance through being "Indigenized" by embracing Indigenous knowledges to inform the content and practice of engineering:

What's missing? The Native point of view. That's the only thing that I think can propel us into the future. And that's where I feel like we're going to be engineers, man. Us Indians. We're the Indianeers.

This comment then becomes quite profound when cast against a different comment from the focus group postulating the formation of an Indian Corps of Engineers in response to the role of the Army Corps of Engineers overseeing construction of the Dakota Access Pipeline. The students wanted Indigenous people to be the engineering leaders for their own communities.

\subsection{Understandings of Leadership}

The reason students wanted to see Indigenous engineering leaders working on the problems facing their communities is rooted in their perception of the purpose of leadership. Participants considered leadership to be a tool for uplifting their communities. For one, several participants viewed themselves as trailblazers, leading young people in their home communities, especially their young family members and their future families, down a new path. They wanted to set an example. Being a trailblazer was defined as "being passionate about something and inspiring other people to want to do the same thing." Ashley wanted others to think "Oh they did it, why can't I?" Ethan commented on being the older sibling who was a first-generation student (high school and college) in the USA: "[I'm] just trying to show [my sister] you can lead your own life." He went on to say he wanted to be a good example because of the difficulties his sister faces in her generation of young people and as a first-generation student.

Family was a primary motivator when it came to trailblazing. Another motivator was the students' criticisms of where they were coming from. They went as far as to say they were "the first person to not act backwards" or where they were from people were stuck in "wretched things", such as making fast money. These criticisms were made from a place of empathy, though, in that participants were sensitive to the way members of their communities were struggling. From their perspective, participants recognized the ways their communities back home were constrained, and they saw their role as offering empowerment. For J-man, humility and empathy are essential: "Furthermore, I think you just have to say too, 'Hey man, I'm not anything man.' We got to remain humble." The students felt for people who were inhibited by the hardships facing their home communities, many of which are caused by settler colonialism's continued impact on Indigenous peoples. 
The carceral system was one of the oppressive forces Ethan described as holding down his family. He was proud to say, because he finished high school, his nephew went to auto mechanic school, and his niece is going to college, a task that should not be taken for granted in his community. Ethan described his niece texting him, "You're the first one to do it." It was very clear to him that he was a trailblazer improving the lives of people he is close to.

Victor, who was raised in a predominantly white community still said all leaders should care about is "how can they help get their people better." Leaders should ask themselves one yes or no question: "this going to hurt somebody or not?" He specified that he did not just mean physical harm but also factors affecting finances, emotions, time spent with family, etc. It "is moving beyond yourself."

\subsection{Community Uplift and Collective Leadership}

Because students felt leadership should be used to uplift one's community, leadership simultaneously was described in both individual and collectivist ways. The students acknowledged that they were doing something that not many had done before them, but they were clear that they were motivated by a desire to improve their communities. The conversation moved from being about the difficulty of being the first to take a different path to the way a leader is inherently in community with others. "It's not leader; it's leaders" was how Ethan described it. He wanted a seat at the table, but he did not see the point in being at the table if he was the only person there. He was lukewarm on the idea of calling himself a leader because "you always learn from everyone else, because there's always going to be something I need help with." Ashley agreed with Ethan but went on to say she did not feel like a leader most of the time but called herself a "little leader" because of her family, especially the women on the reservation, who she inspired by going to school for engineering. Similarly, Victor described how reciprocity is inherent to good leadership. He felt that a leader who cared for their people would in turn be cared for by those people.

J-man described how this form of leadership, which is often referred to as servant leadership, had been observed historically within a Native American context, particularly through the initial period of European contact in North America. He talked about how he looked up to his ancestors who engaged in a degree of self-sacrifice toward the protection of the community. As an example, he described how chiefs would embark on vision quests when their communities faced the threat of smallpox to seek guidance:

[The chiefs] who I looked up to, they are so bad ass... Sometimes it was dire... When smallpox happened, they went out there and someone would go and put themselves out there. . But it was like they would do a lot of bodily harm too sometimes. They would fast, they wouldn't eat they would go out there to die. Just to find help. To help their people.

He contrasted this form of leadership with today's practices, emphasizing how leadership needed to be more community-minded again: "People don't do that anymore. We're all self-preservationists now. You know what I mean? We have to prepare our people."

J-man spoke with passion about leadership historically and in the present. Victor was also interested and opinionated on what a good leader was, a concept he learned from his father. He defined leadership as follows:

You can talk all the talk you want. Everyone can talk until they're blue, but if somebody just starts picking up rocks and moving it over to the other side, now eventually enough people will start picking up rocks and moving it too.

In this case, not only was a leader willing to serve their community, but they also recognized their responsibility as a role model to others.

\subsection{Nuances in Leadership}

In addition to examples of good leadership, students also described the ways leadership had been harmful to their home communities. In many instances, it was their own community leaders who were not acting in the community's best interests. They saw 
their own political leaders as misleading their communities, typically unintentionally, on important issues such as water rights. J-man recounted, "Our legislators and people that were supposed to help us, like our leaders, they were spewing the things that they were told." His decision to major in chemical engineering was informed by the misinformation he saw in his community. Similarly, Ethan, whose aunt had married a Shoshone man, explained that "[The Shoshone have] done things for so long and then they get told by someone that they think they trust because it's going to benefit the area. Then, later on they find out it's not how things work." Having engineering knowledge puts these students in the position to protect Indigenous land and communities in ways political leaders may not.

Victor provided an example in which not owning up to misleading people and admitting a mistake had significant consequences. He brought up former President Donald Trump's comments during the COVID-19 pandemic on injecting bleach to fight the virus. It was unclear to Victor whether this was a malicious comment or a misstep. According to Victor, Trump's appropriate response should have been, "I misspoke yesterday. Sorry, everyone does it. You know, I misspoke." Victor disappointedly followed up with, "he can't do that," and proceeded to discuss how vulnerability and humility were key to good leadership. Victor highly values self-reflection, so he turned inward to understand his leadership development. In a hypothetical, he reflected on unethical leadership by a US military member who was later charged with war crimes: "If I was in Afghanistan with this dude and he was doing that, would I have had the balls to be able to say no?" he pondered. Victor and the other students' cultural and personal backgrounds inspired them to value ethics in leadership. The positives and negatives of the nature of leadership were clear to the students, and they aspired to be better.

\section{Discussion}

The purpose of this study was to explore how four Indigenous engineering undergraduates developed engineering leadership identity. What we learned across these four cases was that these students viewed becoming engineers and exercising leadership as opportunities to improve the lives of communities such as those in which they grew up. Engineering offered a sense of technical expertise that helped them solve pressing problems in their home communities, and leadership is a process of being of service to those who had given much to them. Becoming Indigenous engineering leaders also meant recognizing that Indigenous people had always been engineers, just not using the same language and frames of reference as the European settlers and USA occupiers have for the past few centuries.

In many ways, the findings are quite similar to findings in our other work exploring engineering leadership identity with predominantly white students. In those samples, students also readily identify the need for perseverance to succeed in an engineering program, gain self-efficacy through authentic engagement with engineering practice, and find engineering work fun and enjoyable. Similar to the Indigenous group, past groups were clear about the perseverance it takes to succeed in difficult classes [9]. They also are reluctant to call themselves engineers prior to holding a degree and being licensed to practice, but recognition by others, especially people with some legitimacy in the field, does help them feel closer to seeing themselves as engineers.

The findings diverge when students discuss what the field of engineering means to them as Indigenous people. This was most noticeable when they talk about leadership both in and outside of engineering. First, the underrepresentation of Indigenous and other minoritized students in engineering was a salient point that affected their experience in engineering and provided motivation for them to enter the field. To some extent, as most participants in this study are also first-generation college students, their experiences in engineering are a lot like other first-generation college students. Many first-generation college students note the unfamiliarity of the college environment and having few, if any, college-educated role models to help them navigate the college system. However, further than having access to college-educated role models, it was also quite evident to the partici- 
pants that they had few Indigenous engineering role models to look up to as they embarked on this journey. For our participants, these role models provided a motivating factor not only for their decision to enter engineering but to assume a role as an engineering leader for other Indigenous youth who might be considering a career in engineering. The participants recognized how a career in engineering could be transformative for them as individuals, for their families, and for their communities.

That said, participants described a vision for engineering that went beyond increasing the numerical representation of Indigenous people in the field. One might describe this vision as Indigenizing engineering itself through a reclamation of the ways Indigenous people traditionally engaged in practices that might be called engineering, as well as integrating Indigenous knowledges into science and engineering. These discussions mirrored literature that looks to reorient engineering practice toward a holistic betterment of society [31] and points reflected in Cech et al.'s [17] study on epistemological dominance in science, engineering, and health fields:

I mean, Native Americans were great engineers prior to 1492... They had built their waterways and trade routes and stuff, and many of the current highways and waterways today are built over those. So I think it's just... going into engineering by going back to their ancestry to how they originally were engineers to begin with, too. ( $p$. 753)

These points were also reflected in students' discussions of leadership. For the most part, participants described leadership as a process that facilitates community uplift in support of community sovereignty. In our prior work, we focused on the shifts students made from either equating leadership with management or viewing leadership as emanating from particular organizational roles to a relational process of influence that can be exercised by any member of an organization. Instead, these four participants focused on the outcomes of leadership; the ends targeted by the process of leadership development. Serving as a role model to other family members, making sacrifices of oneself to seek wisdom to guide a community, and combatting the role of misinformation in misleading people to make self-defeating choices were all offered as examples of where leadership should be directed. Participants' core perspectives on leadership were that leaders should have courage, be humble, and be one with their communities. An individual may choose to exercise leadership in a given scenario, but that individual needs to be in relationship with-and accountable to-their community to exercise leadership that best serves their interests [20]. A similar concept was echoed by a participant in Minthorn's [19] study:

"I am only because they are," so I think that's one thing that motivates me. The whole reason I'm doing this is for my community, not for me ( $p$. 82).

The leadership findings from this group were congruent with other research on Indigenous leadership, specifically the emphasis on the importance of collaborative and community-based leadership $[19,26]$. These perspectives also aligned with research on Indigenous students' experiences in STEM with respect to their motivations for entering STEM, as well as research on other minoritized students' experiences in STEM [10].

As a whole, Indigenous students experience engineering identity in similar ways to how engineering identity has been described in the literature, but they also felt that Indigenous knowledges had much to offer the field of engineering due to the ways Indigenous communities have long engaged practices we would today refer to as "engineering". Their understanding of leadership was not only focused on how leadership happens but on the ends toward which leadership is oriented: community uplift that restores the sovereignty of First Nations. Engineering leadership, then, in this context, would encompass the application of engineering practice toward community uplift. As such, Indigenous engineering leadership might be understood in a decolonizing sense: the restoration of traditional knowledge in engineering practice toward reasserting the sovereignty of First Nations in the USA, a promising direction for future research in this area.

However, this vision for engineering leadership clashes with hegemonic views in engineering that the field remain "depoliticized" [33], focused on seemingly neutral values 
such as "objectivity" and "meritocracy," not recognizing that the racialized and gendered nature of engineering practice embeds bias into current practices viewed as objective and meritocratic. Reckoning with these embedded biases and reorienting engineering practice toward more socially just ends [34] could also expand the potential for broadening the participation of Indigenous and other minoritized people in engineering in ways that helps these communities sustain the autonomy and agency needed to address their needs and interests.

\section{Limitations}

This work is meant to continue a pathway toward more research focused on engineering leadership identity among minoritized populations. More work, especially by Indigenous researchers who may have more extensive baseline knowledge of the subject and first-hand experiences to inform their perspectives, would greatly benefit the literature on this subject matter. The COVID-19 pandemic reduced the breadth of perspectives captured in this work by cutting short recruitment and data collection from Indigenous students and future work should seek to add additional breadth. A study with increased numbers of Indigenous students, diversity in nations/bands, location, and other factors could be helpful in seeking saturation of data in this area.

\section{Conclusions}

This work contributes to the research conversation on Indigenous student leadership and the experiences of Indigenous students in STEM fields by investigating the intersection of multiple identity constructs. This work indicates that Indigenous engineering students bring additional perspectives to the nascent field of Engineering Leadership Identity further indicating that this identity construct needs further research. Furthermore, the unique viewpoints on engineering and leadership expressed by the four Indigenous students who participated in this work highlight new ways of thinking that engineering education could benefit from incorporating. Specifically, Engineering Leadership development can provide a method for uplifting communities in a way that is responsive and accountable to those same communities. Engineering educators should seek ways to make this be a mainstream value as it provides a source of intrinsic motivation to Indigenous students and the potential to benefit others from groups traditionally underrepresented in the profession. In other words, Indigenous students would benefit from the validation of Indigenous perspectives on engineering and leadership validated and taught in engineering degree programs, and the engineering profession as a whole could benefit if mainstream engineering thinking was conceptualized in an Indigenous learning framework [17].

Author Contributions: Conceptualization, B.E.H., M.K. and T.S.; Methodology, B.E.H., M.K., W.J.S. and T.S.; Formal Analysis, B.E.H., M.K., W.J.S. and T.S.; Writing-original draft preparation, B.E.H., M.K. and W.J.S.; Writing-review \& editing, B.E.H., M.K., W.J.S. and E.W.; Project Administration, W.J.S.; Funding Acquisition, B.E.H. and W.J.S. All authors have read and agreed to the published version of the manuscript.

Funding: This research and the APC was funded by the National Science Foundation, grant number EEC-1664231. Any opinions, findings, and conclusions or recommendations expressed in this material are those of the authors and do not necessarily reflect the views of the National Science Foundation. Additional support for this work provided by the Undergraduate Scholars Program at Montana State University.

Institutional Review Board Statement: The study was conducted according to the guidelines of the Declaration of Helsinki, and approved by the Institutional Review Board of Montana State University in accordance with the Code of Federal regulations, Part 46, section 101, paragraph (b) (2), approval WS120418-EX, 4 December 2018.

Informed Consent Statement: Informed consent was obtained from all subjects involved in the study.

Data Availability Statement: The data presented in this study are available on request from the corresponding author. The data are not publicly available to uphold participant confidentiality. 
Conflicts of Interest: The authors declare no conflict of interest.

\section{References}

1. National Academies of Sciences; Engineering and Medicine. Promising Practices for Addressing the Underrepresentation of Women in Science, Engineering, and Medicine: Opening Doors; National Academies Press: Washington, DC, USA, 2020.

2. Sochacka, N.W.; Walther, J.; Rich, J.R.; Brewer, M.A. A Narrative Analysis of Stories Told about Engineering in the Public Discourse: Implications for Equity and Inclusion in Engineering. Stud. Eng. Educ. 2021, 2, 54. [CrossRef]

3. Godbole, A.; Miller, B.; Bothwell, M.K.; Montfort, D.; Davis, S.C. Engineering Students' Perceptions of Belonging through the Lens of Social Identity. In Proceedings of the 2018 CoNECD-The Collaborative Network for Engineering and Computing Diversity Conference, Arlington, VA, USA, 29 April-2 May 2018.

4. Hughes, B.E.; Schell, W.J.; Tallman, B.; Beigel, R.; Annand, E.; Kwapisz, M. Do I Think I'm an Engineer? Understanding the Impact of Engineering Identity on Retention. In Proceedings of the 2019 ASEE Annual Conference \& Exposition Proceedings; ASEE Conferences, Tampa, FL, USA, 16-19 June 2019.

5. Tonso, K.L. Engineering Identity. In Cambridge Handbook of Engineering Education Research; Johri, A., Olds, B.M., Eds.; Cambridge University Press: Cambridge, UK, 2014; pp. 267-282.

6. Lee, R. Morrill Act of 1862 Indigenous Land Parcels Database. High Country News, 30 March 2020.

7. Battiste, M. Decolonizing Education: Nourishing the Learning Spirit; UBC Press: Vancouver, BC, Canada, 2017.

8. Schell, W.J.; Hughes, B.E.; Tallman, B.; Sybesma, T.; Kwapisz, M.; Annand, E.; Ranch, S. How Do Students View Leadership Identity in Engineering? In Proceedings of the AAEE 2019 Conference Brisbane, Brisbane, Australia, 8-11 December 2019.

9. Schell, W.J.; Hughes, B.E.; Tallman, B.; Sybesma, T.; Kwapisz, M.; Annand, E.; Bozic, C.; Krejci, C.C.; Kotys-Schwartz, D.A. Understanding the Joint Development of Engineering and Leadership Identities. Eng. Manag. J. 2021, 1-11. [CrossRef]

10. Shotton, H.; Lowe, S.; Waterman, S. Beyond the Asterisk: Understanding Native Students in Higher Education; Stylus Publishing: Sterling, VA, USA, 2013.

11. Brickhouse, N.W.; Lowery, P.; Schultz, K. What Kind of a Girl Does Science? The Construction of School Science Identities. J. Res. Sci. Teach. 2000, 37, 441-458. [CrossRef]

12. Godwin, A.; Lee, W. A Cross-sectional Study of Engineering Identity during Undergraduate Education. In Proceedings of the 2017 ASEE Annual Conference \& Exposition Proceedings, Columbus, OH, USA, 25-28 June 2017.

13. Meyers, K.L.; Ohland, M.W.; Pawley, A.L.; Silliman, S.E.; Smith, K.A. Factors relating to engineering identity. Glob. J. Eng. Educ. 2012, 14, 119-131.

14. Pierrakos, O.; Beam, T.K.; Constantz, J.; Johri, A.; Anderson, R. On the development of a professional identity: Engineering persisters vs engineering switchers. In Proceedings of the 2009 39th IEEE Frontiers in Education Conference, San Antonio, TX, USA, 18-21 October 2009; pp. 1-6.

15. Godwin, A. The Development of a Measure of Engineering Identity. In Proceedings of the 2016 ASEE Annual Conference \& Exposition Proceedings, ASEE Conferences, New Orleans, LA, USA, 26-29 June 2016.

16. Komives, S.R.; Owen, J.E.; Longerbeam, S.D.; Mainella, F.C.; Osteen, L. Developing a Leadership Identity: A Grounded Theory. J. Coll. Stud. Dev. 2005, 46, 593-611. [CrossRef]

17. Cech, E.A.; Metz, A.; Smith, J.L.; de Vries, K. Epistemological Dominance and Social Inequality: Experiences of Native American Science, Engineering, and Health Students. Sci. Technol. Hum. Values 2017, 42, 743-774. [CrossRef]

18. Foster, C.H.; Jordan, S.S. A Philosophy of Learning Engineering and a Native American Philosophy of Learning; An Analysis for Congruency. In Proceedings of the 2014 ASEE Annual Conference \& Exposition, Indianapolis, IN, USA, 15-18 June 2014.

19. Minthorn, R.S. Perspectives and Values of Leadership for Native American College Students in Non-Native Colleges and Universities. J. Leadersh. Educ. 2014, 13, 67-95. [CrossRef]

20. Johnson, V.; Benham, M.K.P.; Van Alstine, M.J. Native Leadership: Advocacy for Transformation, Culture, Community, and Sovereignty. In The Renaissance of American Indian Higher Education: Capturing the Dream; Routledge: New York, NY, USA, 2003; pp. 149-166.

21. Tippeconnic, J. Identity-based and Reputational Leadership: An American Indian Approach to Leadership. J. Res. Leadersh. Educ. 2006, 1, 1-3. [CrossRef]

22. Begay-Campbell, S. Walking in Beauty on an Ever-Changing Path: A Leadership Perspective from a Native American Woman Engineer. Leadersh. Manag. Eng. 2010, 10, 150-152. [CrossRef]

23. Lave, J.; Wenger, E. Situated Learning: Legitimate Peripheral Participation. Learning in Doing; Cambridge University Press: Cambridge, UK, 1991; p. 138.

24. Wenger, E. Communities of Practice: Learning, Meaning, and Identity; Cambridge University Press: Cambridge, UK, 1998.

25. Carlone, H.B.; Johnson, A. Understanding the science experiences of successful women of color: Science identity as an analytic lens. J. Res. Sci. Teach. 2007, 44, 1187-1218. [CrossRef]

26. Wise-Erickson, L.J. Community-Based Leadership: A Study of American Indian Leadership; Seattle University: Seattle, WA, USA, 2003.

27. Montana Office of Public Instruction. Indian Education for All. 2021. Available online: https://opi.mt.gov/Educators/TeachingLearning/Indian-Education-for-All (accessed on 8 October 2021).

28. Grande, S. American Indian identity and intellectualism: The quest for a new red pedagogy. Int. J. Qual. Stud. Educ. 2000, 13, 343-359. [CrossRef] 
29. Brayboy, B.M.J. Toward a Tribal Critical Race Theory in Education. Urban Rev. 2005, 37, 425-446. [CrossRef]

30. Quinn, W.W., Jr. Federal Acknowlegment of American Indian Tribes: The Historical Development of a Legal Concept. Am. J. Legal Hist. 1990, 34, 331. [CrossRef]

31. Anderson, I.; Jordan, S.S. Engineering Connections in a Native American Community and Culture. In Proceedings of the 2018 ASEE Annual Conference \& Exposition, Salt Lake City, UT, USA, 24-27 June 2018.

32. Chilton, M. "How Rain Man Shaped our Image of Autism; Thirty Years Ago, a Film about an Autistic Man Moved the World, but It Didn't Tell the Whole Truth" National Post; Don Mills, ON, Canada. 28 November 2018. Available online: https: / / www.proquest.com/newspapers/how-rain-man-shaped-our-image-autism-thirty-years/docview/2138997082/se-2? accountid $=28148$ (accessed on 8 October 2021).

33. Cicek, J.S.; Steele, A.; Gauthier, S.; Mante, A.A.; Wolf, P.; Robinson, M.; Mattucci, S. Indigenizing Engineering education in Canada: Critically considered. Teach. High. Educ. 2021, 1-22. [CrossRef]

34. Cech, E.A.; Sherick, H.M. Depoliticization and the Structure of Engineering Education. In International Perspectives on Engineering Education; Springer: Berlin/Heidelberg, Germany, 2015; pp. 203-216. 